\title{
Dry machinability analyses between free cutting, resulfurized, and carbon steels
}

\author{
D. Martinez Krahmer, G. Urbicain \& A. J. Sánchez Egea
}

To cite this article: D. Martinez Krahmer, G. Urbicain \& A. J. Sánchez Egea (2020): Dry machinability analyses between free cutting, resulfurized, and carbon steels, Materials and Manufacturing Processes

To link to this article: https://doi.org/10.1080/10426914.2020.1734615

\section{Published online: 26 Feb 2020.}

Submit your article to this journal 주

Q View related articles ¿

View Crossmark data $\nearrow$ 


\title{
Dry machinability analyses between free cutting, resulfurized, and carbon steels
}

\author{
D. Martinez Krahmer (10) ${ }^{a, b}$, G. Urbicain $\mathbb{1}^{c}$, and A. J. Sánchez Egea (10) ${ }^{d}$
}

aCentro de Investigación y Desarrollo en Mecánica, Instituto Nacional de Tecnología Industrial INTI, Provincia de Buenos Aires, Argentina; ${ }^{\text {'Faculty }}$ of Engineering, Universidad Nacional de Lomas de Zamora, Provincia de Buenos Aires, Argentina; 'Department of Mechanical Engineering, Faculty of Engineering of Bilbao, Aeronautics Advanced Manufacturing Center (CFAA), Bilbao, Spain; dDepartment of Mechanical Engineering (EEBE), Universitat Politècnica de Catalunya, Barcelona, Spain

\begin{abstract}
Free cutting steels, also referred to as free machining steels, include free cutting additives to improve tool life and machinability. Despite their wide applications in industry, scarce information is available to ensure reliable, safe, and productive cutting operations. This work presents a comparative study of the machinability of different free cutting steels to realize their real behavior and potential as alternatives to conventional steels. Three free cutting steels (SAE 12L14, 11L17, and 11L41), a resulfurized steel (SAE 1144), and a low-carbon steel (SAE 1010) were experimentally investigated employing turning tests. Key process parameters such as wear evolution, surface roughness, and material adhesion were analyzed. The results showed that low cutting speeds tend to improve tool life in free cutting steels, while this advantage disappears at high cutting speeds. Energy-dispersive X-ray spectroscopy analyses showed that chemical elements, such as $\mathrm{Mn}, \mathrm{S}$, and, especially $\mathrm{Pb}$, play a significant role in self-lubrication at the cutting tool tip, thus reducing tool wear at low and medium cutting speeds. Besides, thermal simulations were done to verify the correspondence between material properties, machinability, and thermal field in the tool/chip interface.
\end{abstract}

ARTICLE HISTORY

Received 15 November 2019 Accepted 18 February 2020

\section{KEYWORDS}

Machinability; turning; adhesion; wear; roughness; simulation

\section{Introduction}

Machining processes are accurate but expensive finishing operations where cutting parameters must simultaneously satisfy productivity and safety. Regarding both aspects, tool life is a crucial parameter since it will determine the quality and surface integrity of the machined part and the number of parts that could be done. It is a direct indicator of how good or bad are the selected cutting conditions. Despite its importance, it can only be measured indirectly by tracing a wear curve, depending on the cutting conditions and the stop criterion of wear, to determine the duration of tool tip edge. The earliest model that stated the relationship between the service life of the cutting tool edge and the cutting conditions was Taylor's model. ${ }^{[1]}$ By using Taylor's equation, tool life can be characterized by relating the cutting parameters, the type of material, and the tool geometry (radius, edge preparation, chip breaker, etc.). Suresh et al. ${ }^{[2]}$ thoroughly described most of the intrinsic factors (roughness, surface hardness, residual stresses, etc.) and extrinsic factors (cutting conditions, tool material, tool geometry, machine rigidity, etc.) that affect the cutting capabilities of hard steels. Tool's requirements are particularly challenging in the case of difficult-to-cut materials. Valdivielso et al. ${ }^{[3]}$ presented an interesting approach for the definition of the best insert properties (coating, chip breaker, geometry, etc.) when turning low machinability materials. Polvorosa et al. ${ }^{[4]}$ studied the influence of cooling techniques (6 and 80 bar) on tool wear mechanisms through face turning tests on Inconel 718 and Waspalloy. They found that large grain alloy structure results in higher notch wear, while smaller structure leads to higher flank wear. Lately, Amini et al. ${ }^{[5]}$ stated the importance of machining in near dry machining to improve the surface roughness and minimize the tool wear in stainless steel. They also observed that dry machining brings worse surface roughness mainly due to built-up edge at the tool tip, which promotes higher friction forces and, consequently, a higher tool wear compared with the near dry machining.

Specifically, free cutting steels (FCS) or free machining steels are carbon steels with free cutting additives than had been broadly used in the automotive sector. ${ }^{[6]}$ These additives (often $\mathrm{S}, \mathrm{Pb}, \mathrm{Sn}, \mathrm{Se}, \mathrm{Te}$, or $\mathrm{Bi}$ ) are added to improve machinability. Free machining steels significantly contribute to the reduction of machining costs with lower cutting forces and longer tool life. ${ }^{[7]}$ Their main advantages are short chips and reduced contact length in the tool/chip interface, thus reducing the friction power, heat, tool wear, etc. ${ }^{[8]}$ There are different classifications, but FCS can be divided into four main subtypes: ${ }^{[9]}$ leaded $(\mathrm{Pb})$, resulfurized $(\mathrm{S})$, rephosphoresced $(\mathrm{P})$ and resulfurized $(\mathrm{P}+\mathrm{S})$, and super $(\mathrm{Te}+\mathrm{Se}+\mathrm{Bi})$. The percentage of these additives have to accomplish standard of Restriction of the use of certain Hazardous Substances in electrical and electronic equipment (RoHS Directive), ${ }^{[10]}$ due to environmental considerations; ${ }^{[11]}$ because there is a lack of information regarding their machinability. Concerning these FCS, Almeida et al. ${ }^{[12]}$ investigated the influence of lead, sulfur, and manganese on machinability. They

CONTACT A. J. Sánchez Egea antonio.egea@upc.edu E Department of Mechanical Engineering (EEBE), Universitat Politècnica De Catalunya, Av. Eduard 
reported the incidence of these elements in turning tests using coated hard metal inserts at high cutting speeds (between 400 and $500 \mathrm{~m} / \mathrm{min}$ ). As a result of the tests, they stated that machinability is very sensitive to the percentage of $\mathrm{Cu}$ in the steel grade. However, more experiments should be done, for instance, combining uncoated inserts with low cutting speeds, and further analysis should be made in the cutting tip to determine the material adhesion. Jinyang and coworkers ${ }^{[13]}$ investigated about nontoxic FSC that were turned using coated and uncoated inserts. They established that the activation of the wear mechanisms was significantly lower in the coated inserts due to the formation of manganese sulfide tribofilms which significantly reduced the wear rate. They reported that this type of adhesion did not occur in the uncoated inserts, although all the tests were performed at a very high cutting speed $(500 \mathrm{~m} / \mathrm{min})$, which is not recommended for uncoated inserts. Furthermore, Ray et al. ${ }^{[14]}$ studied the relationship between inclusions and machinability of FCS. They analyzed the effect of cold deformation on the interinclusion spacing and the aspect ratio of the inclusions. Also, Wang et al. ${ }^{[15]}$ compared the machinability of free cutting austenitic stainless steels. They proved that these steels reduced cutting forces with regard to a more conventional austenite stainless steel $(1 \mathrm{Cr}-18 \mathrm{Ni}-9 \mathrm{Ti})$ at the studied cutting speed range. Desaigues et al. ${ }^{[16]}$ analyzed via an exhaustive experimental study the BuiltUp Layer (BUL) formation during machining of high-strength FCS. They measured cutting forces and temperatures and examined the cutting inserts with SEM (EDX) after a set of turning experiments. They found that BUL was composed of MnS adhesion coming from the workpiece. Also, Varghese et al. ${ }^{[1]}$ performed a relational analysis to study the influence of the machining parameters on the output process conditions in dry turning of $11 \mathrm{SMn} 30$ FCS. They obtained the related surface responses for the surface roughness and defined optimum cutting conditions. Recently, Martinez-Krahmer et al. ${ }^{[18]}$ performed round turning tests on three grades of FCS under dry and wet machining conditions by using an uncoated hard metal insert to determine the wear curves. They found the MnS layer adhered in the rake face of the cutting inserts machined in dry condition. This compound acted as an auto lubrication film with better performance than the conventional oil-based lubricant. Nevertheless, the influence of different FCS on the tool performance of uncoated inserts (thermal degradation, material adherence, wear, etc.) has not been adequately addressed, in order to select the cutting speed and type of material based on the volume of chip removed (productivity). In this sense, the novelty of this work deals with the characterization via experimental test and simulation approach of the lifespan of tool edge by selecting the proper cutting conditions based on the FCS to cut in dry conditions.

Therefore, the aim of the present work is to analyze the machinability of different grades of carbon steels during a dry turning operation. Three of the tested materials are FCS (12L14, 11L17, and 11L41), while the other two are resulfurized steel (1144) and a low-carbon steel (1010). Several cutting parameters were studied and modeled. First, wear progression and surface roughness were studied at different cutting speeds. Second, in order to explain tool degradation, thermal simulations were used. The temperature field in the chip and other critical parameters to cutting mechanics (shear temperature, friction power, temperatures at the toolchip interface, etc.) were predicted for an FCS and a more common steel. Besides, surface roughness was examined for a range of cutting speeds, showing the path for an adequate definition of tool replacement, i.e., satisfying productivity and safety. The definition of suitable cutting parameters is crucial in the industry where there is a lack of knowledge, especially in FCS.

\section{Materials and methods}

\section{Experimental conditions}

Table 1 lists the five materials to be studied (SAE 12L14, SAE 11L17, SAE 11L41, SAE 1144, and SAE 1010). These were supplied in drawn bars of $38.1 \mathrm{~mm}$ in diameter and $350 \mathrm{~mm}$ in length. The bars are laminated, normalized, and, finally, cold worked in a unique drawing step. Table 1 summarizes the chemical composition (\% by weight) and hardness values (Brinell), which were measured with optical emission spectroscopy (model: LAB M8 - Serial number 10363/98) and Instron Wolpert durometer (model: S8-233971). Note that FCS' lead content is always below 0.24 (in wt\%) according to the RoHS Directive. ${ }^{[10]}$

Then, a set of dry turning operations were done in a CNC lathe (Promecor SMT 19 with $20 \mathrm{~kW}$ ) using uncoated rhombic inserts (CNMG120408, ISO P40). The nose radius was $0.8 \mathrm{~mm}$, and the insert mounted in the toolhoder (MCLNR-2525M12) results in the following positioning: rake angle of $\gamma=-4^{\circ}$, clearance angle of $\alpha=5^{\circ}$, and inclination angle of $\lambda=-5^{\circ}$.

Table 2 presents the cutting conditions from the tool supplier's recommendations. To track wear evolution, an optical measuring bench (Dormer, model $\mathrm{N}^{\circ} 94$, serial number G472) was used to measure tool wear at different time steps. Despite the standard criterion of $V_{B}=0.3 \mathrm{~mm}$ established in ISO $3685,{ }^{[19]}$ the wear stop criterion was here set at $V_{B}=0.5 \mathrm{~mm}$. The reason is to be able to register more points, due to the fast wear rate of the uncoated inserts during the experiments. Finally, surface roughness was measured with the Surtronic 3+ roughness tester (from Taylor Hobson(C).

SEM microscope (FEI model: QUANTA 250 FEG) was utilized to determine the main wear parameters. Besides, an energydispersive X-ray spectroscopy (EDS) module (UTW-Sapphire,

Table 1. Chemical composition (\%wt) and material hardness (HB) of the tested materials.

\begin{tabular}{|c|c|c|c|c|c|c|c|}
\hline Material & C (\%wt) & Mn (\%wt) & $\mathrm{S}$ (\%wt) & $\mathrm{P}$ (\%wt) & $\mathrm{Pb}$ (\%wt) & $\mathrm{Fe}(\% \mathrm{wt})$ & $\mathrm{HB}$ \\
\hline SAE $12 \mathrm{~L} 14$ & 0.08 & 1.07 & 0.320 & 0.058 & 0.24 & Balance & 161 \\
\hline SAE $11 \mathrm{~L} 17$ & 0.16 & 1.14 & 0.103 & 0.018 & 0.23 & Balance & 155 \\
\hline SAE $11 \mathrm{~L} 41$ & 0.40 & 1.53 & 0.100 & 0.019 & 0.22 & Balance & 161 \\
\hline SAE 1144 & 0.42 & 1.53 & 0.304 & 0.024 & 0 & Balance & 248 \\
\hline SAE 1010 & 0.10 & 0.45 & 0.040 & 0.030 & 0 & Balance & 165 \\
\hline
\end{tabular}


Table 2. Cutting parameters for the turning tests.

\begin{tabular}{lcccc}
\hline$V_{c}(\mathrm{~m} / \mathrm{min})$ & $f(\mathrm{~mm} / \mathrm{rev})$ & $a_{p}(\mathrm{~mm})$ & Type of lubricant & $V_{B}(\mathrm{~mm})$ \\
\hline $150-180-240$ & 0.125 & 1.25 & None & 0.5 \\
\hline
\end{tabular}

model: PV7760/79 ME) was used to investigate the presence of chemical elements on the tribofilm layer. Finally, material adhesion and tool tip degradation were observed with InfiniteFocus optical surface profiler (from Alicona()).

\section{Numerical simulation}

As the simulation of the temperature field in the chip and friction at the tool-chip interface is a good way to compute tool degradation, thermal simulations were conducted to relate carbon steel grade with tool tip wear. The followed approach was similar to the model presented in, ${ }^{[20]}$ which has proven to be enough accurate to assess the temperature field on the chip and chip/rake interface zones. The main assumptions were the following: (1) chip removal process considered as a continuous material flow passing through the shear plane and being instantly heated and (2) the temperature along the whole shear plane length $\left(T_{s}\right)$ is constant. Table 3 shows the main parameters for the thermal simulations to compare SAE 12L14 with respect to SAE 1010 grade.

So, the thermal problem was formulated in $1 \mathrm{D}$ assuming a control volume (the chip) moving along the tool-chip interface, while the heat convection is neglected. The shear plane defines the border between the undeformed $h_{1}=f$ and deformed $h_{2}=h_{1} / \tan \varphi$ chip thicknesses. The shear plane angle is computed following the Merchant's assumption: ${ }^{[21]}$

$$
\varphi=\frac{\pi}{4}+\frac{\gamma}{2}-\frac{\beta}{2}
$$

where $\gamma$ is the rake angle and $\beta$ is the friction angle at toolchip interface. For an orthogonal (and longitudinal) turning, $\beta$ can be computed from:

$$
\tan (\beta-\gamma) \approx \frac{F_{z}}{F_{y}}
$$

where the $\mathrm{z}$-axis is in the direction of a longitudinal turning test and the $y$-axis is in the direction of the cutting speed (tangential direction). From a set of orthogonal cutting tests, the cutting force components $F_{z}$ and $F_{y}$ can be obtained for the calculation of $\beta$ angle and so for the estimation of $\varphi$ angle (using Eq. 1). Therefore, thermal conditions given in Table 3 are completed with conditions given in Table 4, from force measurements. The cutting conditions are taken from the performed experimental tests, which are common cutting conditions used to machine FCS. ${ }^{[7,13]}$

Table 3. Mechanical and thermal properties for the cutting of SAE $12 \mathrm{~L} 14$ and SAE 1010 .

\begin{tabular}{llcccc}
\hline & Materials & $\rho\left[\mathrm{kg} / \mathrm{m}^{3}\right]$ & $c_{p}\left[\mathrm{~J} / \mathrm{g}-{ }^{\circ} \mathrm{K}\right]$ & $\kappa\left[\mathrm{W} / \mathrm{m}-{ }^{\circ} \mathrm{K}\right]$ & $\delta\left[\mathrm{m}^{2} / \mathrm{s}\right]$ \\
\hline Work materials & $12 \mathrm{~L} 14$ & 7,870 & 0.47 & 51.9 & 14.03 \\
& 1010 & 7,870 & 0.47 & 49.8 & 13.46 \\
Insert (uncoated) & $\mathrm{CW}$ & 14,250 & 0.25 & 80 & 22.46 \\
\hline
\end{tabular}

Table 4. Cutting conditions for thermal simulations with SAE $12 \mathrm{~L} 14$ and SAE 1010.

\begin{tabular}{lcccccc}
\hline Materials & $V_{c}[\mathrm{~m} / \mathrm{min}]$ & $a_{p}[\mathrm{~mm}]$ & $f[\mathrm{~mm} / \mathrm{rev}]$ & $K_{s}[\mathrm{MPa}]$ & $\varphi\left[^{\circ}\right]$ & $\beta\left[^{\circ}\right]$ \\
\hline \multirow{2}{*}{$12 \mathrm{~L} 14$} & 150 & 1.25 & 0.125 & 2,050 & 34.65 & 24.71 \\
& 180 & & & & 34.44 & 25.12 \\
\multirow{4}{*}{1010} & 240 & & & 2,600 & 31.01 & 31.56 \\
& 150 & & & & 29.65 & 34.97 \\
& 180 & & & & 28.54 & 36.92 \\
\hline
\end{tabular}

Finally, the temperature field within the chip can also be calculated. Once fixed $\varphi$ and $\beta$ for a given cutting condition, the temperature at the shear plane can be computed as:

$$
T_{s}=\frac{K_{s} \cdot \cos (\varphi+\beta)}{\rho \cdot c_{p} \cdot \cos \varphi \cdot \cos \beta}
$$

where $K_{s}$ is the specific cutting energy for the pair workpiece-tool.

\section{Results and discussion}

\section{Wear evolution}

Wear progression and the corresponding Taylor curves were determined for the five studied steel grades at three cutting speeds. Figure 1 exhibits the wear evolution versus tool life in dry machining tests for each steel grade, where the polynomial adjustment curves are defined $\left(R^{2}\right.$ minimum $\left.=0.966\right)$ to obtain the trend of tool life while reaching the wear criterion of $V_{B}=0.5 \mathrm{~mm}$.

For cutting speeds of $240 \mathrm{~m} / \mathrm{min}$, no noticeable differences were found in tool life for the five steel grades, where the cutting tool reaches the stop criterion of $V_{B}=0.5 \mathrm{~mm}$ in about $20 \mathrm{~min}$. On the contrary, the wear curves denote that the steel grades that contain lead present a remarkably longer tool life of the insert when using cutting speeds of 150 and $180 \mathrm{~m} / \mathrm{min}$. Additionally, the two steel grades without lead show a low machinability because the service life of the cutting tool was about $35 \mathrm{~min}$ in the best scenario. Consequently, these results are expected because of the self-lubrication characteristics of the lead during dry cutting, despite its toxicity. ${ }^{[2]}$ Comparing different leaded steels, it is denoted that the percentage of carbon in the steel grade is also an important aspect for reducing the wear progression and, subsequently, increasing the service life of the cutting tool. SAE 11L41 contains more than twice the percentage of carbon than the SAE 11L17, and consequently, the tool life for a cutting speed of 150 or $180 \mathrm{~m} /$ min is about twice shorter. Figure 2 shows the Taylor curves for the five studied carbon steel grades that were turned with an uncoated insert, where polynomial adjustment curves were used $\left(R^{2}\right.$ minimum $\left.=0.99\right)$. In this sense, it is defined as the wear trend when using the same machining conditions. The slope indicates the wear speed of the insert for specific machining conditions, as defined in Table 2.

Based on the slope of the different Taylor curves, it is characterized how the steel grades and cutting speeds affect tool life. Particularly, FCS are more dependent on cutting speed than the other two lead-free steels, despite that the 

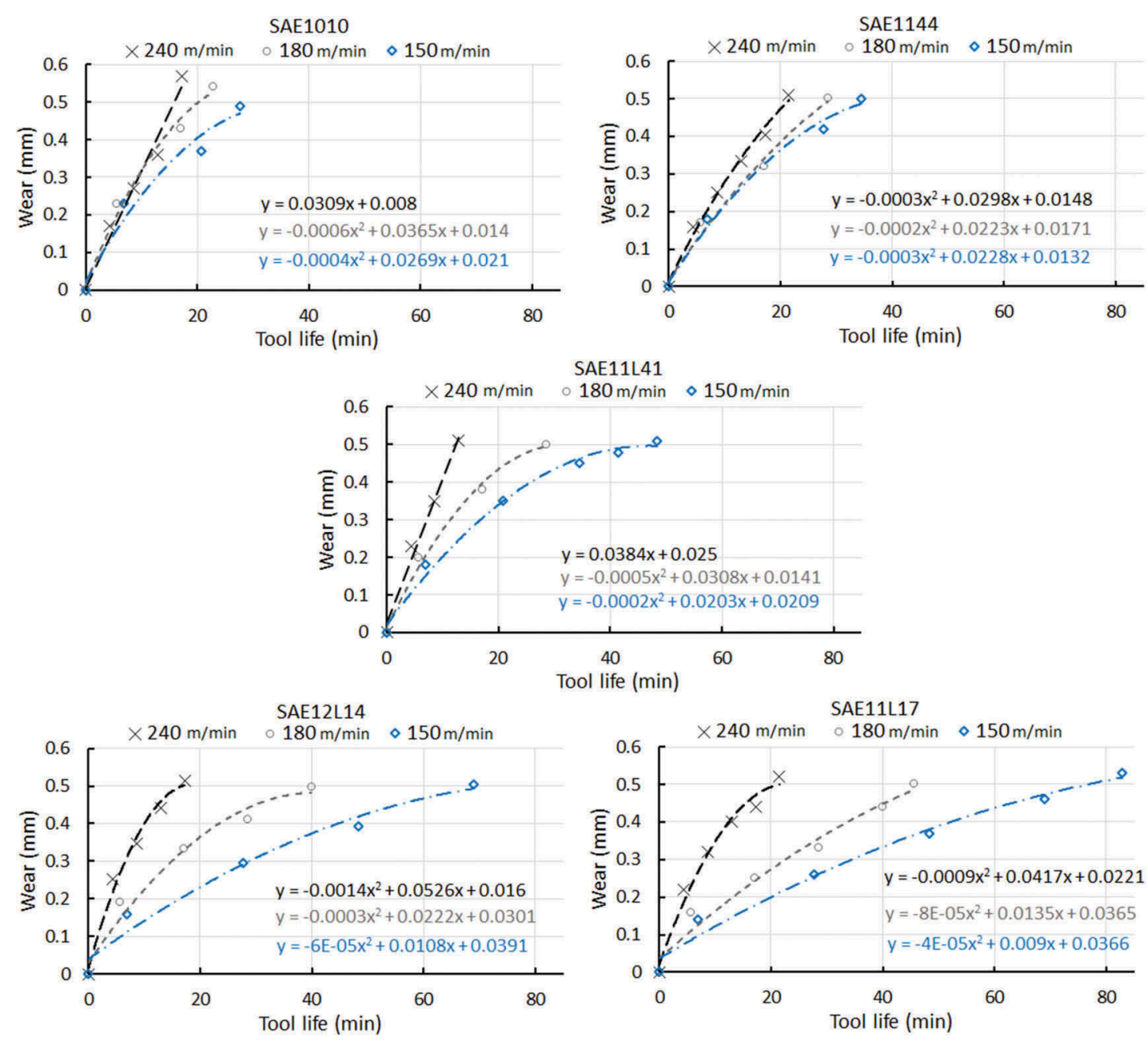

Figure 1. Wear curves and the corresponding polynomial fitting.

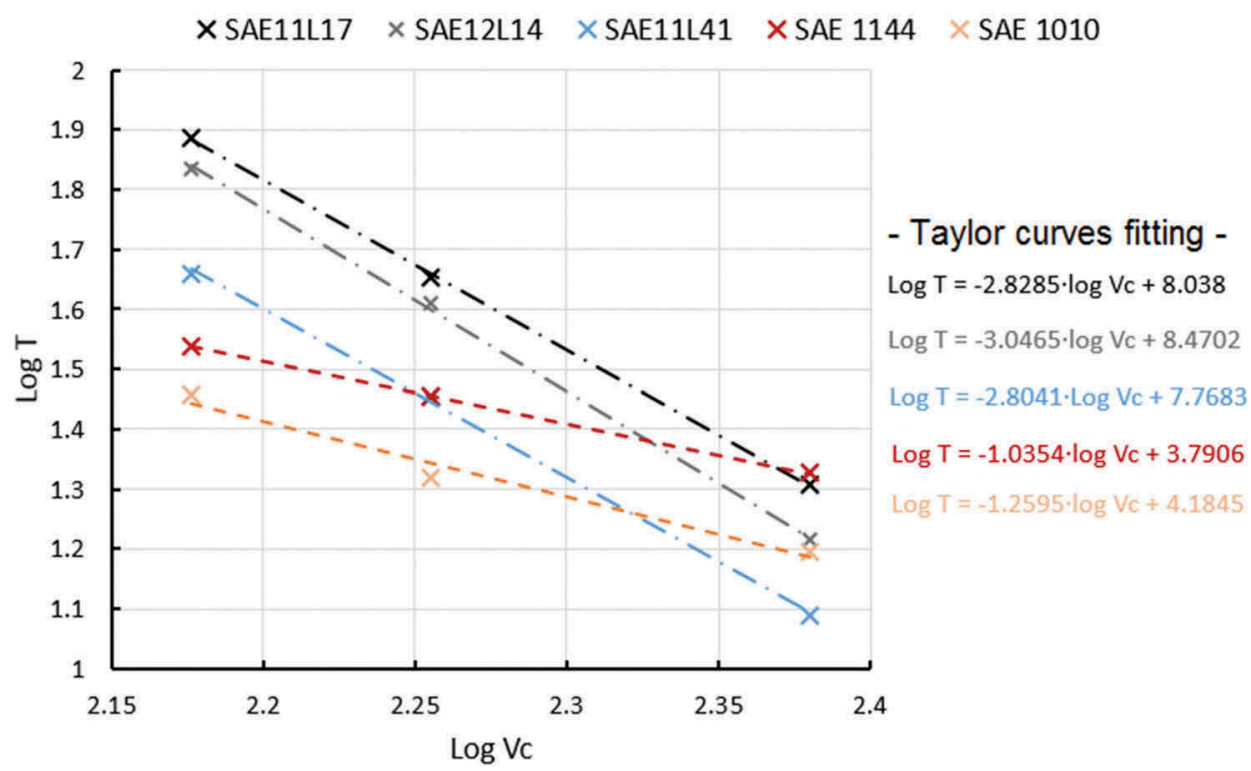

Figure 2. Taylor curves and fitting for the tested steel grades.

slope is similar among the FCS, as also reported by $\mathrm{Xu}^{\left[{ }^{[23]} \mathrm{At}\right.}$ high cutting speeds, tool life dramatically decreases for FCS and present a similar performance than the lead-free steels.
However, the steel grade with longer tool life is not necessarily the steel grade with a higher percentage of $\mathrm{Pb}, \mathrm{S}$, or $\mathrm{Mn}$. With respect to the cutting speeds, at $240 \mathrm{~m} / \mathrm{min}$, tool life 
when machining SAE 1144 is about $20 \mathrm{~min}$, while for SAE 11L41 is almost half of that time. Therefore, the benefit of using FSC is highly dependent on the selected cutting speed and should be studied case by case.

\section{Removed volume computation}

Figure 3 depicts the material removed at the wear stop criterion of $V_{B}=0.5 \mathrm{~mm}$ for each steel grade and the above cutting conditions. These results are a good indicator of the tool's performance for each of the tested materials.

In terms of chip removal, lead-free carbon steels present a quite uniform trend regardless of cutting speed. Regarding leaded steel grades, a higher mass removal rate is noticed at low cutting speeds. For higher speed, the amount of removed material is lower than the unleaded material. The best cutting performance was found in SAE $11 \mathrm{~L} 17$ at $150 \mathrm{~m} / \mathrm{min}$, achieving a chip volume of $7,400 \mathrm{~cm}^{3}$. On the contrary, the worst case was found in SAE 11L41 when turning at $240 \mathrm{~m} / \mathrm{min}$, achieving a volume of $1,800 \mathrm{~cm}^{3}$. Subsequently, the removed material found for each steel grade is in agreement with the experimental results found in Fig. 2, where leaded steels present longer tool life when using lower cutting speed and, consequently, higher material can be cut. Note that the chemical compound that contains the FSC is crucial for the tool life and chip removal because the formation of $\mathrm{MnS}, \mathrm{Pb}$, and/or other tribofilm layer will explain the differences of tool life between the steel grades.

\section{Investigation on tribological mechanisms}

In dry cutting processes, material adhesion has a significant influence on self-lubrication mechanisms, ${ }^{[24,25]}$ and accordingly, it is directly related to the lifespan of the cutting tool and the final surface roughness. In this sense, Fig. 4 shows the worn tool tip obtained when reaching the wear criterion by using the cutting tool speed of $150 \mathrm{~m} / \mathrm{min}$. Then, EDS was used to determine the chemical elements, such as $\mathrm{Mn}, \mathrm{S}$, and $\mathrm{Pb}$, at the different tool faces of the cutting tool. These compounds behaved like a tribofilm at the interface decreasing the friction between the material and tool interface and, consequently, reduced the wear at the tool tip. ${ }^{[22]}$ According to Table 1, all the steel grades except SAE 1010 present a certain amount of $\mathrm{Mn}$ and $\mathrm{S}$ to find adhesion of the $\mathrm{MnS}$ on the tool tip, particularly when low cutting speed is used. By comparing the leaded steels, it is observed that the $\mathrm{Pb}$ brings a remarkable difference in tool life when using low and medium cutting speeds, as shown in Fig. 1. There is no difference between them at high cutting speed because the temperature affects the influence of lead as a tribofilm. With respect to this aspect, Han et al. ${ }^{[26]}$ also reported the auto lubrication properties of $\mathrm{Pb}$ in steels while they were processed. Therefore, the percentage of $\mathrm{Mn}, \mathrm{S}$, and $\mathrm{Pb}$ seems to be decisive for extending the tool life and increase the chip removal volume ${ }^{[8]}$, because of the formation of tribofilm layer at the tool-workpiece interface will explain the differences of tool life between the steel grades.

An EDS analysis was conducted on the material adhesion found in SAE 1144 and SAE 12L14 to study the presence of $\mathrm{MnS}$ and $\mathrm{Pb}$, as shown in Fig. 5. The error bars represent the standard deviation of five measurements in the same areas of interest (crater and flank wear). It was observed that both the percentages of $\mathrm{Mn}, \mathrm{S}$, and $\mathrm{Pb}$ were significantly higher in inserts when using low cutting spindle speeds. At the seame time, $\mathrm{Mn}$ and $\mathrm{S}$ present similar values for low and medium cutting speeds and decrease for high cutting speeds. On the contrary, the percentage of lead decreases when increasing the cutting speed. Therefore, the self-lubricant mechanisms of such components are potentiated at low cutting speeds.

\section{Surface roughness comparison}

As surface quality is a good indicator of cutting performance and tool degradation, the average surface roughness $\left(R_{a}\right)$ values were represented for all the tested materials. Figure 6 shows these values, which were calculated from six

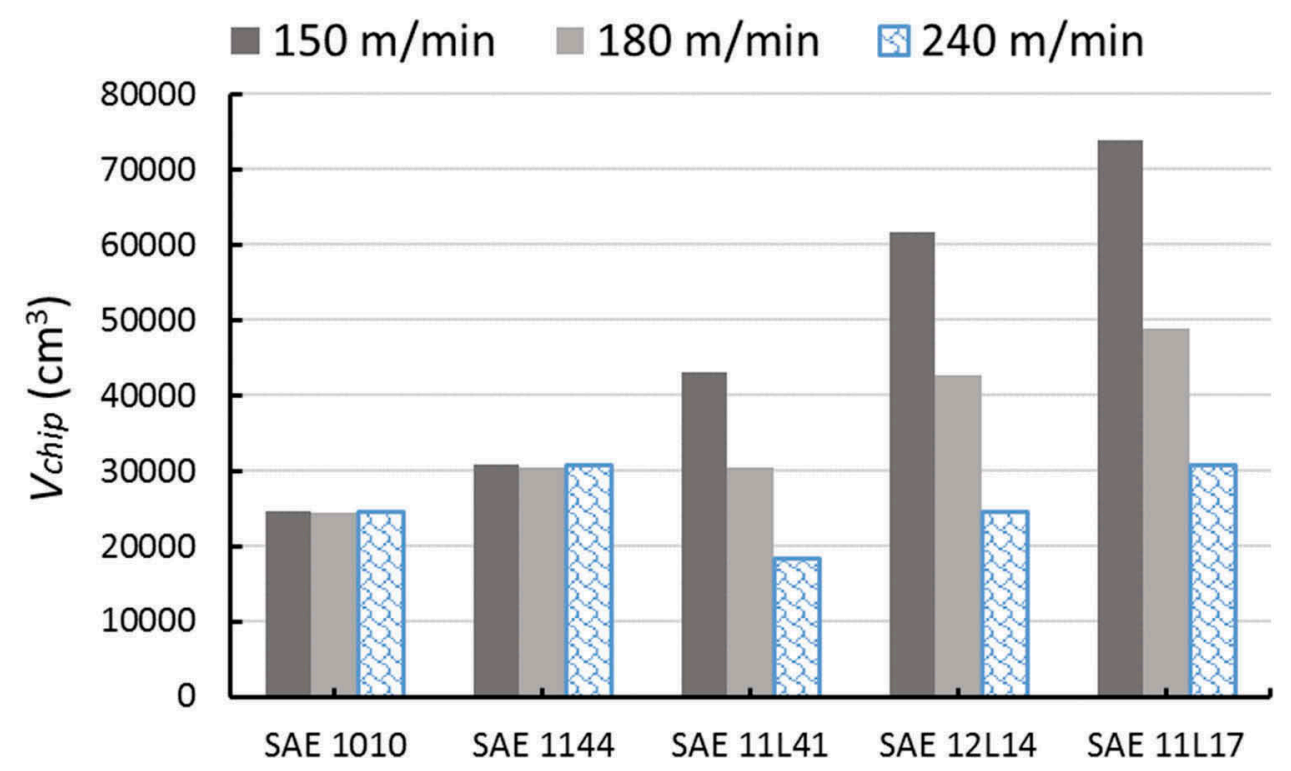

Figure 3. Material removed at the wear stop criterion for the tested steel grades. 

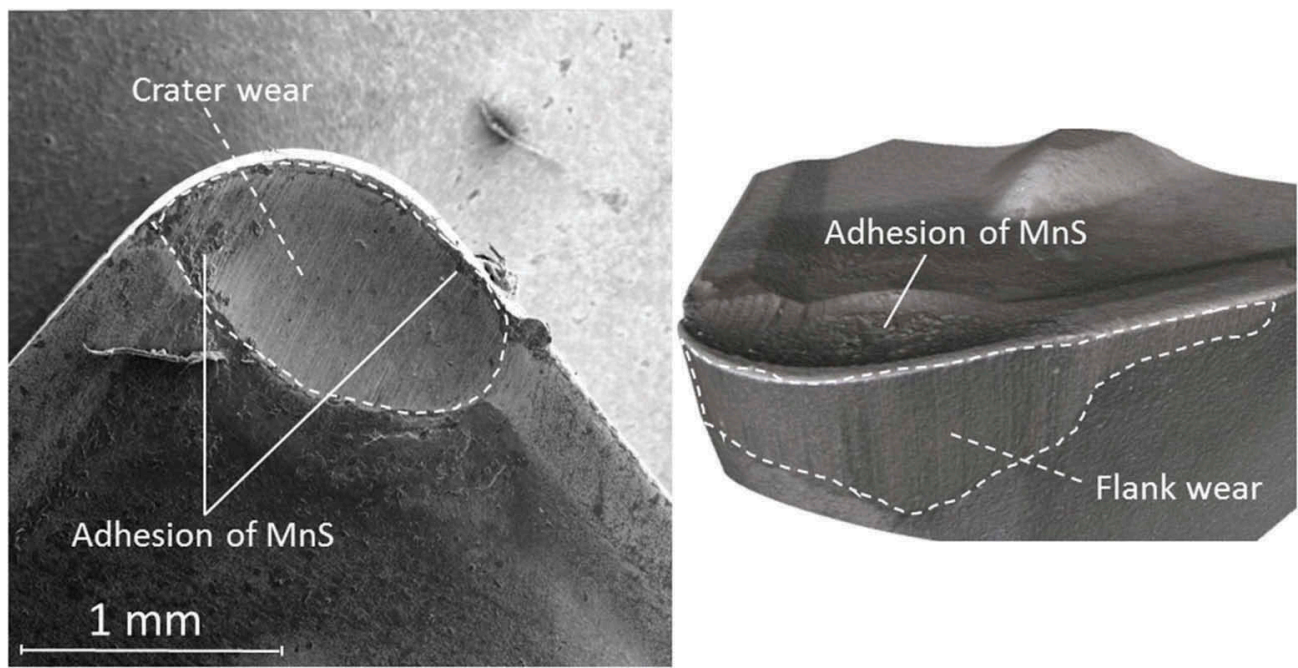

Figure 4. Microscope images of the worn tool tip tested with $150 \mathrm{~m} / \mathrm{min}$ to show tool wear and material adhesion.

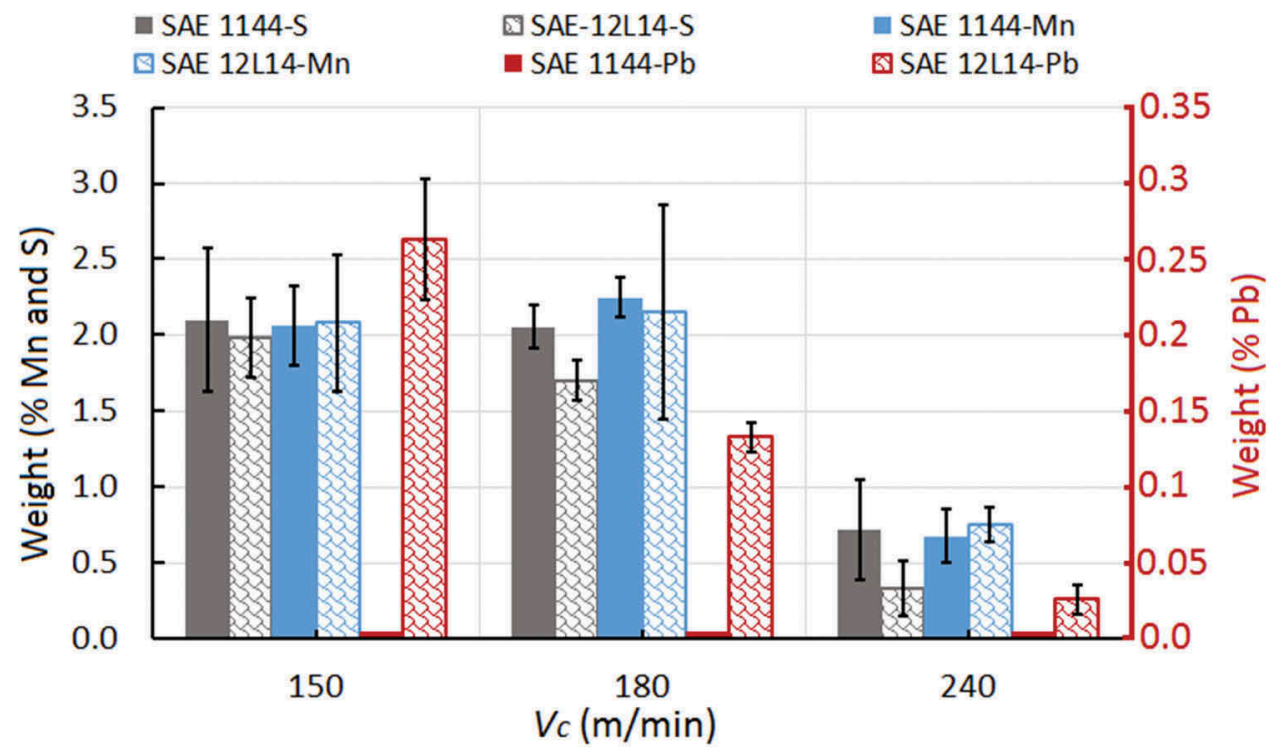

Figure 5. Percentage of weight of $\mathrm{S}, \mathrm{Mn}$, and $\mathrm{Pb}$ at the tool tip for the different cutting speeds in added material found at the tool tip after cut SAE $12 \mathrm{~L} 14$ and $\mathrm{SAE} 1144$.
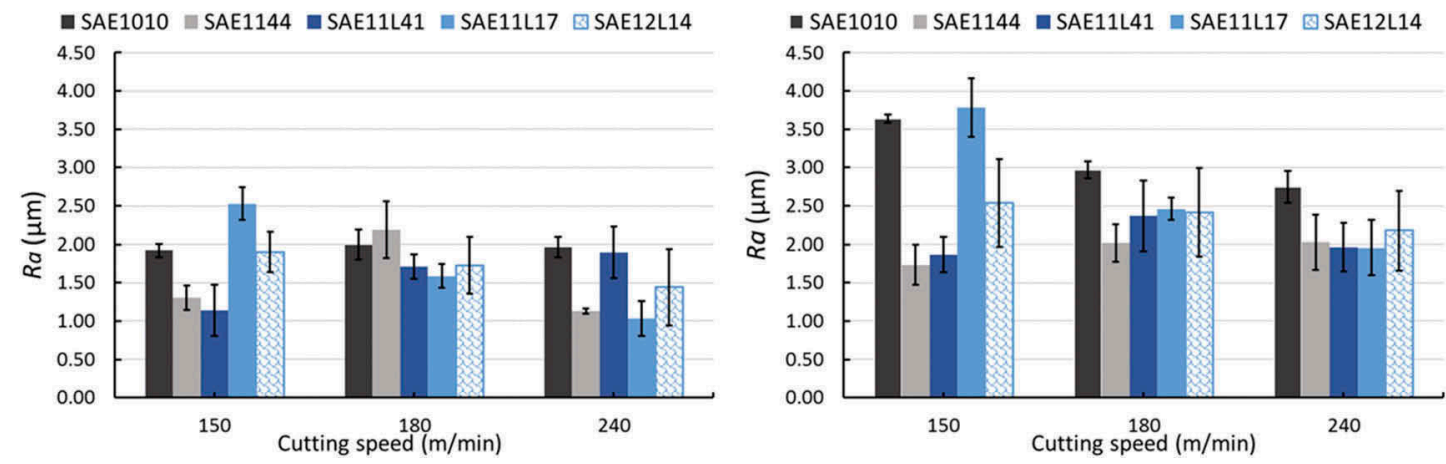

Figure 6. Average surface roughness for the five cutting speeds: (a) new inserts (at first pass) and (b) worn inserts (at $V_{B}=0.5 \mathrm{~mm}$ ).

measurements, at the beginning of tool life (first pass) and at the stop criterion (worn insert with $V_{B}=0.5 \mathrm{~mm}$ ). The margin errors are represented by the standard deviations.
It is well known that the surface roughness closely depends on (a) the feed rate which is fixed for all the tests and materials; (b) the tool nose morphology (new versus worn 
inserts), where the loss of radius of the tool tip makes the surface roughness more inconsistent, so the standard deviations should be higher for the worn insert at $V_{B}=0.5$; (c) the cutting speed, where high cutting speeds tend to generate better finishes (not always, but it is a trend that can be seen in the two figures, at $V_{B}=0$ and $V_{B}=0.5$ ); and (d) the type of material, where similar values of surface roughness are found for all the steel grades except the SAE 1010 that presents the worst scenario, due to mainly its low machinability which can be only partially compensated at high speeds (see Fig. 2). The lowest surface roughness of $1 \mu \mathrm{m}$ was found when turning SAE 11L17 with a new insert and a cutting speed of $240 \mathrm{~m} /$ min. On the contrary, the highest surface roughness of about $3.6 \mu \mathrm{m}$ was noted when turning SAE 1010 or SAE 11L17 with a worn insert and a cutting speed of $150 \mathrm{~m} / \mathrm{min}$. The surface roughness and the cutting speeds do not indicate an evident distribution. An ANOVA analysis using the general linear model exhibited that, firstly, there are significant differences in the roughness measured with the new edges with respect to the worn edges. Second, there are differences according to the type of steel machined (higher values for SAE 1010 and lower values for SAE 11L41), and lately, the cutting speed does not influence the measured values of average surface roughness.

\section{Evolution of temperature at the tool/chip interface}

Based on the thermal approach described in the method section, the following output results are obtained to understand the wear differences and Taylor curves in the studied steel grades. First, Fig. 7 exhibits the temperature profile along the tool-chip interface for different cutting tool velocities for SAE 12L14 and SAE 1010.

As expected, greater temperatures are observed at the interface when higher cutting speed is used. The highest temperature is found around $0.3 \mathrm{~mm}$ (within the crater shown in Fig. 4) at the tool-chip interface within the range of values of $1,000-1,200^{\circ} \mathrm{C}$. By comparing the two steel grades, higher values are noted along the temperature distribution in the SAE 1010, which can be associated with not having auto lubricant elements, like the lead, that have proved to minimize friction mechanisms at the interface. ${ }^{[12]}$ This leads to better machinability of the FCS 12L14 with respect to 1010 steel. Additionally, Table 5 represents the predicted shear plane temperature $T_{s}$ and the maximum temperature at the tool rake surface $T_{\max }$.

The thermal distribution with respect to the chip height is defined for two different steel grades SAE 12L14 and SAE 1010, as shown in Fig. 8. Thanks to this, the maximum
Table 5. Cutting conditions and the corresponding data from cutting mechanics for the carbon steel SAE 12L14 and SAE 1010.

\begin{tabular}{|c|c|c|c|c|c|c|c|c|}
\hline Materials & $V_{c}[\mathrm{~m} / \mathrm{min}]$ & $\left.\begin{array}{c}a_{p} \\
{[\mathrm{~mm}]}\end{array}\right]$ & $\begin{array}{c}f=h_{1} \\
{[\mathrm{~mm} / \mathrm{rev}]}\end{array}$ & $\begin{array}{c}K_{s} \\
{[\mathrm{MPa}]}\end{array}$ & $\varphi\left[{ }^{\circ}\right]$ & $\beta\left[{ }^{\circ}\right]$ & $\begin{array}{c}T_{s} \\
{\left[{ }^{\circ} \mathrm{C}\right]}\end{array}$ & $\begin{array}{l}T_{\max } \\
{\left[{ }^{\circ} \mathrm{C}\right]} \\
\end{array}$ \\
\hline \multirow[t]{3}{*}{$12 \mathrm{~L} 14$} & 150 & 1.25 & 0.125 & 2,050 & 34.65 & 24.71 & 396 & 854 \\
\hline & 180 & & & & 34.44 & 25.12 & 394 & 904 \\
\hline & 240 & & & & 31.22 & 31.56 & 366 & 1088 \\
\hline \multirow[t]{3}{*}{1010} & 150 & & & 2,600 & 31.01 & 31.97 & 315 & 926 \\
\hline & 180 & & & & 29.65 & 34.71 & 306 & 1026 \\
\hline & 240 & & & & 28.54 & 36.92 & 299 & 1173 \\
\hline
\end{tabular}

temperature and the temperature distribution along the layer of the chip thickness for the different cutting speeds can be found. Finally, the obtained temperature field can be related to the wear progression during the turning tests. A mesh of $500 \times 100$ (500 elements in the tool interface direction and 100 elements in the shear plane direction) rectangular elements were used for the simulations in Fig. 8.

It is important to mention that the used inserts are uncoated, so that the temperature will be the major factor in tool wear progression. For cutting speeds of $150 \mathrm{~m} / \mathrm{min}$, the maximum temperature was about $600^{\circ} \mathrm{C}$ at the chip height range of 0.1 and $0.5 \mathrm{~mm}$ and the chip height lower than $0.02 \mathrm{~mm}$. Regarding the highest cutting speed, the maximum temperature was found around the $1,000^{\circ} \mathrm{C}$ at the chip height range of 0.1 and $0.5 \mathrm{~mm}$, although in this case the influence in the chip height is greater reaching values near to the $0.05 \mathrm{~mm}$. The more significant differences between the two steel grades are that the thermal dissipation in this interface and chip height is better for the SAE 12L14 than for the SAE 1010. Subsequently, SAE 1010 presents poor machinability compared to SAE 12L14, which leads to a more aggressive temperature field, thus accelerating the tool wear rate. This is consequent with the wear values found experimentally, where it was noted that the service life of the tool tips noticeably increased for the SAE $12 \mathrm{~L} 14$ with respect to SAE 1010 for low and medium cutting speeds. In the case of SAE 12L14 and SAE1010, the difference in the thermal field is due more to the specific cutting energy, rather than to the thermal properties, whichare quite similar (see Table 3 ).

\section{Conclusions}

The following study presents an intensive comparison on machinability and wear behavior of uncoated inserts in dry turning of: (1) FCS, (2) sulfurized steel (SAE 1144), and (3) low-carbon steel (SAE 1010). Accordingly, some important conclusions can be drawn:
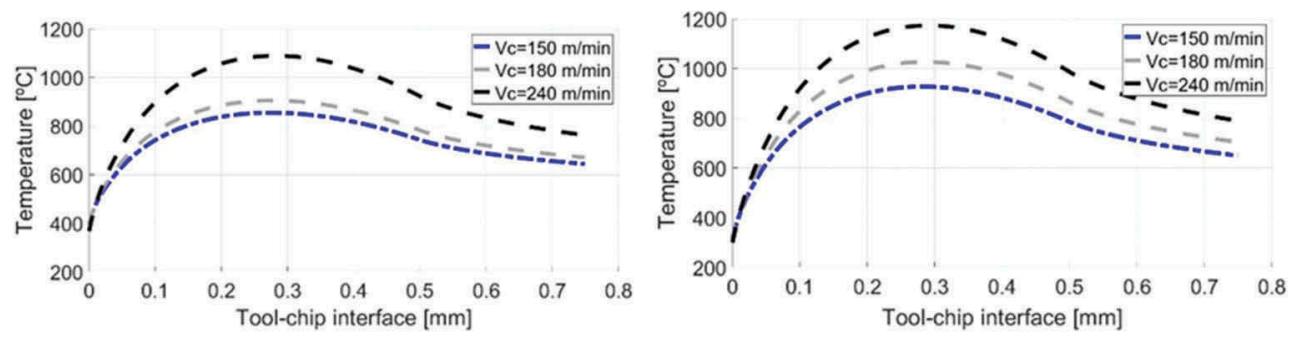

Figure 7. Temperature evolution at the tool-chip interface for different cutting speeds for the steel grades: (a) SAE 12 L14 and (b) SAE 1010. 


\section{$150 \mathrm{~m} / \mathrm{min}$}
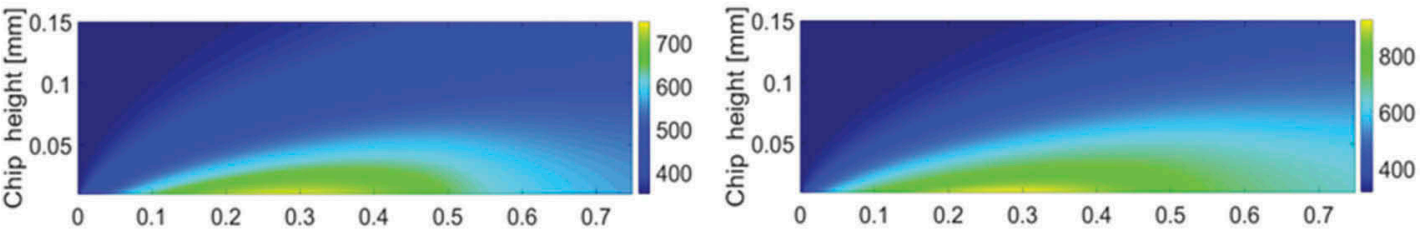

$180 \mathrm{~m} / \mathrm{min}$
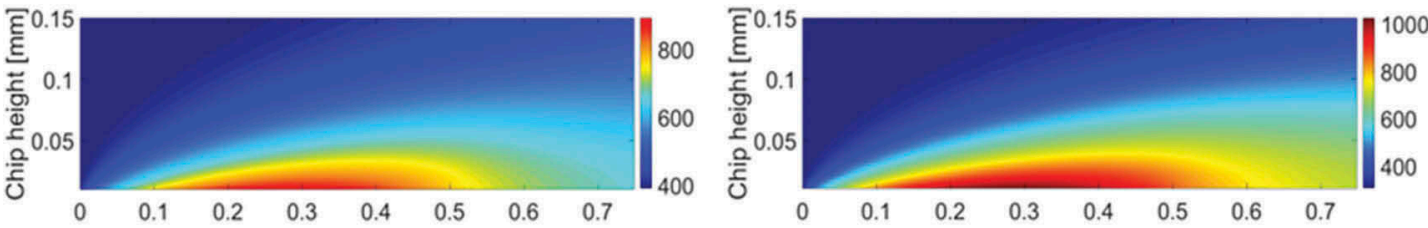

$240 \mathrm{~m} / \mathrm{min}$
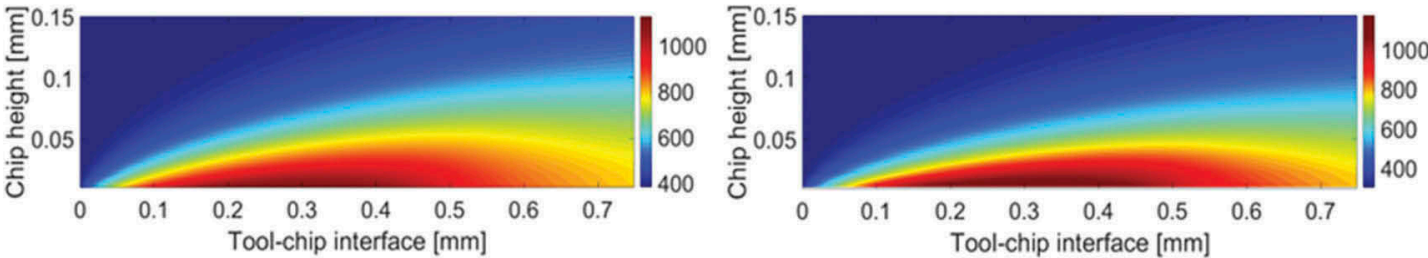

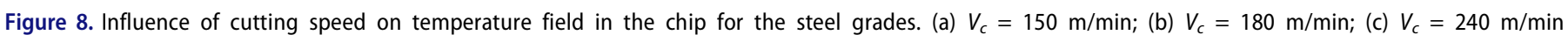
(left: SAE 12L14, right: SAE 1010).

(1) The presence of lead extended the tool life at low and medium cutting speeds between twice and fourth times depending on the FCS. The most productive cutting conditions were found for the FCS at the lowest cutting speed of $150 \mathrm{~m} / \mathrm{min}$.

(2) The volume of the removed material can be doubled with respect to the two tested low/medium-carbon steels. This advantage is progressively reduced at medium cutting speeds $(180 \mathrm{~m} / \mathrm{min})$ and disappears at high cutting speeds $(240 \mathrm{~m} / \mathrm{min})$.

(3) Self-lubrication compounds were observed at the rake face of the cutting tool after machining leaded steels and SAE 1144. Specifically, MnS and $\mathrm{Pb}$ acted as a tribofilm reducing tool wear at low and medium cutting speeds.

(4) On the side of thermal simulations, the machinability coefficient or specific force $K_{s}$ needs to be read with $\left(V_{c}, \mathrm{f}\right.$, and $\left.a_{p}\right)$ which are responsible for the $\varphi$ and $\beta$ angles. The higher the thermal diffusivity $\alpha$, the lower the increase beyond $T_{s}$ of the temperatures (this is also true for $T_{\max }$ ). From this point of view, both simulated materials have similar behavior.

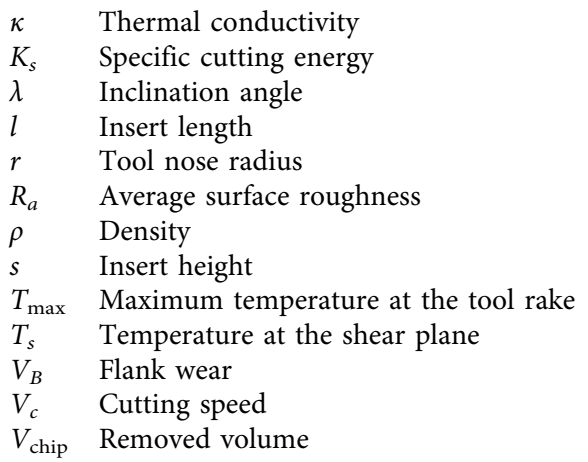

\section{Funding}

This work is supported by the Serra Húnter program (Generalitat de Catalunya) reference number [UPC-LE-304 (2018)]. Besides, the authors are thankful to the Basque Government support in the Basque University group in Advanced manufacturing ref: IT1337-19.

\section{ORCID}

D. Martinez Krahmer (D) http://orcid.org/0000-0002-0184-2168

G. Urbicain (D) http://orcid.org/0000-0002-7159-8199

A. J. Sánchez Egea (D) http://orcid.org/0000-0001-8085-6869

\section{References}

[1] Taylor, F. On the Art of Cutting Metals, 3rd ed.; American society of mechanical engineers, Transactions of the ASME: New York, NY, 1906.

[2] Suresh, R.; Basavarajappa, S.; Gaitonde, V.; Samuel, G.; Davim, J. State-of-the-art Research in Machinability of Hardened Steels. Proc. IMechE Part B: J Eng. Manuf. 2013, 227(2), 191-209. DOI: $10.1177 / 0954405412464589$. 
[3] Fernández-Valdivielso, A.; López de Lacalle, L. N.; Urbikain, G.; Rodriguez, A. Detecting the Key Geometrical Features and Grades of Carbide Inserts for the Turning of Nickel-based Alloys Concerning Surface Integrity. Proc. IMechE Part C: J. Mech. Eng. Sci. 2016, 230(20), 3725-3742. DOI: 10.1177/0954406215616145.

[4] Polvorosa, R.; Suárez, A.; López de Lacalle, L. N.; Cerrillo, I.; Wretland, A.; Veiga, F. Tool Wear on Nickel Alloys with Different Coolant Pressures: Comparison of Alloy 718 and Waspaloy. J. Manuf. Proc. 2017, 26, 44-56. DOI: 10.1016/j. jmapro.2017.01.012.

[5] Amini, S.; Khakbaz, H.; Barani, A. Improvement of Near-Dry Machining and Its Effect on Tool Wear in Turning of AISI 4142. Mater. Manuf. Processes. 2015, 30(2), 241-247. DOI: 10.1080/10426914.2014.952029.

[6] Watari, K.; Iwasaki, T.; Aiso, T. Development of Lead-free Free-cutting Steel and Cutting Technology. Nippon Steel Sumitomo Metal Tech. Rep. 2017, 116, 1-6.

[7] Essel, I. Machinability Enhancement of Nonleaded Free-cutting Steel; Shaker Verlag, 2006, pp p 11. ISBN: 9783832253103.

[8] Chen, Y.; Bao, Y.; Wang, M.; Cai, X.; Wang, L.; Zhao, L. Superior Machinability of Steel Enhanced with BN and MnS Particles. Int. J. Miner. Metall. Mater. 2016, 23(3), 276-282. DOI: 10.1007/ s12613-016-1236-x.

[9] Zivkovic, D.; Štrbac, N.; Ekinovic, S.; Begović, E. Lead-free Free-cutting Steels as Modern Environmentally Friendly Materials. Ecologica 2011, 18, 451-456.

[10] Directive 2011/65/EU of the European Parliament Restriction of the use of certain hazardous substances in electrical and electronic equipment text with EEA relevance, June 8, 2011.

[11] Li, Z.; Wu, D.; Wei, L.; Zheng, Z.; Kang, S. Investigations on Low Environmental Impact Machining Processes of Free Cutting Austenitic Stainless Steels. App. Mech. Mat. 2013, 377, 112-116. DOI: 10.4028/www.scientific.net/AMM.377.112.

[12] Almeida, M.; Ferreira, J.; Luis, N.; Machado, A.; Oliveira, D.; Pimentel, M. Study of the Effect of Residual Elements (Cr, Ni, and $\mathrm{Cu}$ ) on the Machinability of Free-machining Steel AISI 12L14 Using Design of Experiment. Proc IMechE Part B: J. Eng. Manuf. 2010, 224, 1481-1489. DOI: 10.1243/09544054JEM1694.

[13] Jinyang, X.; Zhiqiang, L.; Guo, G.; Ming, C. An Investigation on Wear Mechanism of High-speed Turning of Free-cutting Steel AISI 1215 Using Uncoated and Multi-layer Coated Tools. Int. J. Adv. Manuf. Tech. 2013, 67, 517-533. DOI: 10.1007/s00170-012-4502-8.

[14] Ray, K. K.; Das, J.; Dixit, A.; Chakraborty, M.; Chakravorty, S.; Guha, S. N. Effect of Cold Deformation on the Machinability of a Free Cutting Steel. Mater. Manuf. Process. 2006, 21(4), 333-340. DOI: $10.1080 / 10426910500411488$.

[15] Wang, Z.; Shao, Z.; Li, Z.; Zhang, H.; Wang, J.; Zhang, H.; Yuan, J. Making of Free Cutting Austenitic Stainless Steels with Additions of Sulfur, Rare Earth and Bismuth. 5th Int. Conf. Adv. Des. Manuf. Eng. 2015. DOI: 10.2991/icadme-15.2015.356.

[16] Desaigues, J. E.; Lescalier, C.; Bomont-Arzur, A.; Dudzinski, D.; Bomont, O. Experimental Study of Built-up Layer Formation during Machining of High Strength Free-cutting Steel. J. Mater. Process. Tech. 2016, 236, 204-215. DOI: 10.1016/j.jmatprotec.2016.05.016.

[17] Varghese, L.; Aravind, S.; Shunmugesh, K. Multi-objective Optimization of Machining Parameters during Dry Turning of 11SMn30 Free Cutting Steel Using Grey Relational Analysis. Mater. Today: Proc. 2017, 4, 4196-4203. DOI: 10.1016/j. matpr.2017.02.122.

[18] Martínez-Krahmer, D.; Hameed, S.; Sánchez Egea, A. J.; Pérez, D.; Canales, J.; López de Lacalle, L. N. Wear and MnS Layer Adhesion in Uncoated Cutting Tools When Dry and Wet Turning Free-Cutting Steels. Metals 2019, 9(5), 556. DOI: 10.3390/met9050556.

[19] ASTM E112-13. Standard Test Methods for Determining Average Grain Size; ASTM International: West Conshohocken, PA, 2013. www.astm.org.

[20] Boothroyd, G.;. Temperatures in Orthogonal Metal Cutting. Proc. Inst. Mech. Eng. E. 1963, 177, 789-810. DOI: 10.1243/ PIME_PROC_1963_177_058_02.

[21] Merchant, M. E.; Machining Theory and Practice. Am. Soc. Metals. 1950, 9, 5-44.

[22] Reynolds, P.; Block, V.; Essel, I.; Klocke, F. Alternatives to Lead as a Machinability Enhancer in Free Cutting Steels. Steel Res. Int. 2007, 78(12), 908-914. DOI: 10.1002/srin.200706305.

[23] Xu, J.; An, Q.; Chen, M. Experimental Study on High-speed Turning of Free-cutting Steel AISI 12L14 Using Multi-layer Coated Carbide Tools. Adv. Mater. Res. 2012, 500, 3-7. DOI: 10.4028/www.scientific.net/AMR.500.3.

[24] Omrani, E.; Rohatgi, P. K.; Menezes, P. L. Tribology and Applications of Self-Lubricating Materials; CRC Press, 2017. ISBN: 9781351650113.

[25] Sharma, V.; Pandey, P. M. Comparative Study of Turning of 4340 Hardened Steel with Hybrid Textured Self-Lubricating Cutting Inserts. Mater. Manuf. Process. 2016, 31(14), 1904-1916. DOI: 10.1080/10426914.2015.1127951.

[26] Han, J.; Li, Y.; Jiang, Z.; Yang, Y.; Wang, X.; Wang, L.; Li, K. Summary of the Function of $\mathrm{Sn}$ in Iron and Steel. Adv. Mater. Res. 2013, 773, 406-411. DOI: 10.4028/www.scientific.net/AMR.773.406. 